Sánchez Jareño, Rosa.

\title{
El Museo como escuela de espectadores. La ciudadanía en los Museos de Arte.
}

\section{The museum as a school of spectators. The citizenship in the Art Museums.}

TIPO DE TRABAJO:

Comunicación.

PALABRAS CLAVE:

Museo, sociomuseología, espectador, mediación cultural.

KEY WORDS:

Museum, sociomuseology, spectator, cultural mediation.

\section{RESUMEN.}

El presente trabajo tiene como principal intención reflexionar acerca de las prácticas de dinamización y mediación en el espacio museístico. Cada vez son más los museos que incorporan metodologías que implican la creación de experiencias con el público, ampliando el concepto de museo como mero contenedor cultural. El espacio museístico se convierte también en espacio de encuentro, aprendizaje, ocio y juego. Vemos como estas propuestas son recogidas y aplicadas en mayor o menor medida en las distintas instituciones museísticas, revelando así su grado de compromiso hacia la ciudadanía. Finalmente se realiza un estudio genérico en materia de dinamización museística en los principales museos nacionales.

\section{ABSTRACT.}

The present work has as main intention explore the work of the museums of art at the the socio-cultural animation. The number of museums that are incorporating methodologies that involve the creation of experiences with the public is growing considerably, unfolding the clasical concept of museum as a mere cultural container. The museum becomes also into a space of meeting, learning, leisure and game. We see how these proposals are handled and applied in greater or lesser measure in the different institutions, revealing his degree of commitment to the citizenship. Finally a generic study about museum dynamisation of the most important Spanish museums is presented.

\section{CONTENIDO.}

\section{El Espectador en el punto de mira}

Antes de comenzar es conveniente -al igual que en cualquier función o reunión como la que celebramos en este congreso- que situemos y acomodemos a nuestro público. ¿Qué es el público y porqué prefiero utilizar la palabra espectador en lugar de la de público? En los últimos años se ha venido usando ( $y$ abusando) de la palabra público, del latín, populus, perteneciente al pueblo. Pero el estudio que aquí presento va más allá de una cuestión de algo perteneciente a un público. Mi sujeto de estudio se sitúa en el 
espectador, del latín, espectator, que en una primerísima acepción del término se refería a aquel sujeto que tiene hábito de observar, de mirar, quien ha contemplado algo y es un apreciador crítico. A ese tipo de público espectador es al que señalo, un espectador emancipado como el de Ranciere.

\section{DESARROLLO}

Reconsiderar el museo como una escuela en la que compartir procesos y diálogos es una idea relativamente nueva y que aún no ha llegado a ser implementada en muchas instituciones. El espectador tiene una capacidad crítica activa que se debe contemplar y usar a favor de la institución. Así el museo, debe saber mediar entre su función educativa y legitimadora al mismo tiempo que tiene en cuenta la población en la que se inscribe. La sostenibilidad de muchos museos depende en gran medida, que se comprenda que en su edificio no puede haber únicamente espacio para una comunidad artística consumada (que decide qué es arte), también debe de dar cabida al entramado social y asociativo, puesto que el museo sin sociedad pierde su sentido.

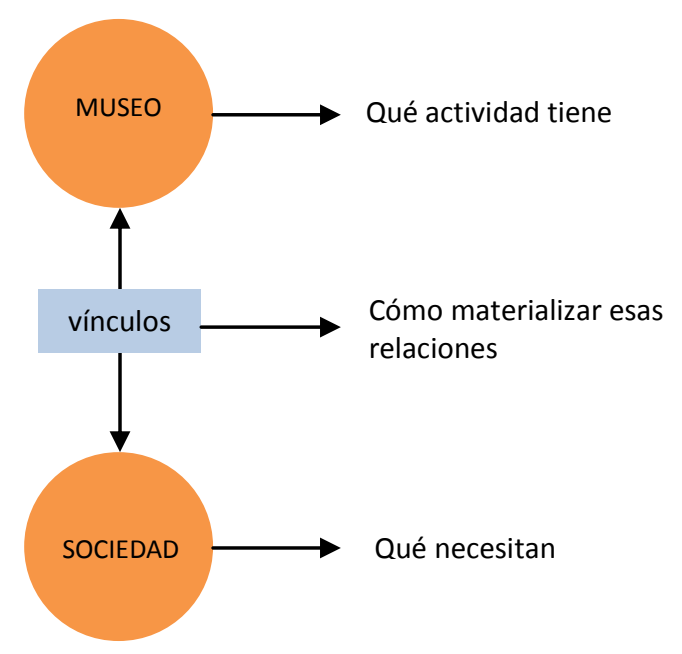

Relación Museo y ciudadanía, 2017. Fuente: elaboración propia a partir de Nina Simon

La evolución de las instituciones museográficas ha ido despojándose de la clásica idea de museo cuya única función era la de servir de contenedor de objetos para protegerlos, preservarlos y exhibirlos. Con la transformación del 'museo como templo' al museo como espacio experiencial se busca que éstos también tengan las funciones de crear, difundir y facilitar el conocimiento. Bajo estas premisas, se debe lidiar con la ardua tarea de servir como espacio de ocio y atractivo turístico, al mismo tiempo que espacio de reunión, estudio, desarrollo local, pero ante todo: de aprendizaje. El cambio de la evolución museográfica también se ve influenciado por el cambio en las corrientes didácticas: algunos autores han señalado que estamos en la cuarta revolución educativa ${ }^{1}$. Esto significa que, al contrario de concebir la educación como algo instructivo y propio de la infancia y juventud, la adquisición de conocimientos es algo que ocurre durante toda la vida y tiene lugar en los distintos contextos interpersonales (trabajo, familia, ocio...etc.). Esta concepción expandida de la educación sitúa las prácticas sociales educativas en tres contextos: el formal, o educación intencional (que corresponde al sistema educativo y tiene como fin la obtención de un título habilitador), el no formal, o educación incidental (aquellas actividades fuera de la educación formal que facilitan la obtención de conocimientos) y el informal (aprendizaje que se da en las experiencias de la vida cotidiana). Podemos considerar los museos como lugares en los que se facilita, por un lado, el aprendizaje no formal e informal, puesto que permite al visitante la obtención de conocimiento, desarrollo de interpretaciones críticas, comprensión de hechos estéticos, socioculturales...etc. Por otro lado también constituye un recurso para la educación formal, ya que puede complementar y ampliar los conocimientos adquiridos en el aula además de potenciar la apreciación por la protección y cuidado de bienes culturales.

\footnotetext{
1 José Joaquinn Brunner relaciona las transformaciones en educación en tres períodos históricos: creación de conventos e instituciones privadas, renacimiento (creación de instituciones públicas) revolución industrial (aparición del texto impreso y masificación de la educación primaria). Situándonos, a día de hoy, en la cuarta revolución, por la llegada del cambio social desatado por las tecnologías de la información.
} 


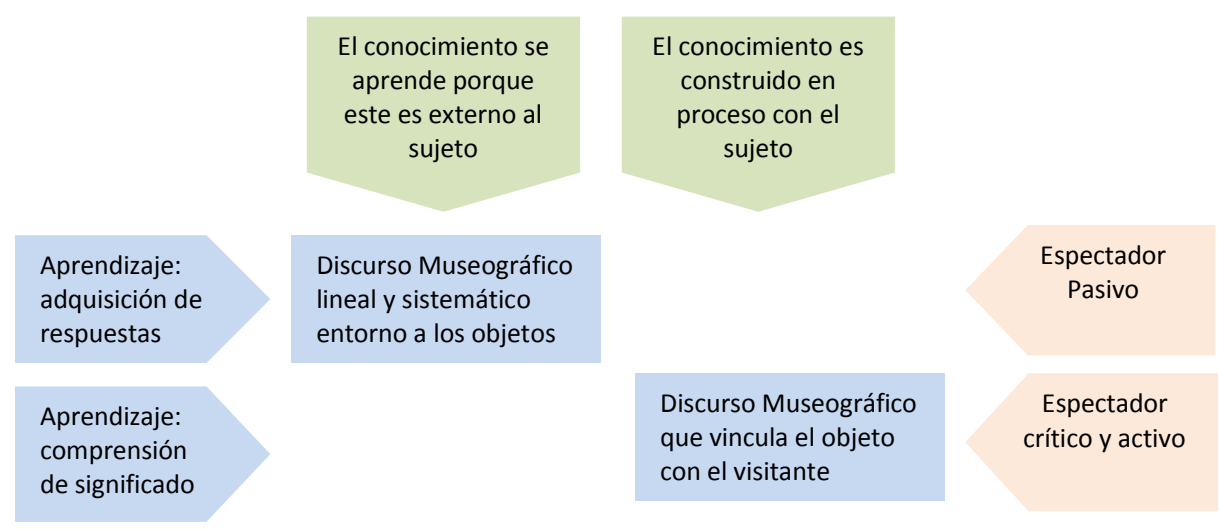

\section{Museografía lineal y museografía vinculante. Fuente: elaboración propia a partir de Hein (1999)}

¿Pero cómo aprenden los espectadores en el museo, es decir, qué herramientas o dispositivos dispone el museo para que el espectador logre conocer los objetos que se exponen? Existen, principalmente, dos líneas museográficas de acuerdo a la concepción de los espectadores:

- Museografía sistemática y lineal: se basa en la concepción de que la estructura de la exposición debe ser totalmente fiel y real al objeto de estudio. De esta forma el contenido se presenta de forma que sea fácilmente comprensible para el espectador

- Museografía constructivista y crítica: el espectador construye a través de sus conocimientos el significado de la exposición, puesto que el propio proceso de adquirir conocimiento es en sí mismo un acto constructivista. ${ }^{2}$

Podemos ver muchos ejemplos de museos que siguen una museografía basada en sistemas lineales. En materia de museos dedicados al arte, hay una gran mayoría de museos de Bellas Artes que presentan sus objetos siguiendo una disposición cronológica o taxonómica. Esto se debe en que, en su gran mayoría los museos de bellas artes arrastran un modelo decimonónico heredado de gabinetes y salas expositivas pensadas principalmente para historiadores del arte. Son museos en los que el discurso no se adapta a los conocimientos y motivaciones del visitante, creando así un espectador pasivo ante la cultura. Por ello, los museos de Bellas Artes son los más susceptibles a cambios e innovación. Por el contrario, en una museografía constructivista las características de los objetos presentados y su documentación no son tan importantes, puesto que el significado de los objetos se construye a través de la atribución personal de sentido de los visitantes. El museo proporciona instrumentos que permiten al espectador interpretar el dispositivo museográfico, observar, pensar, reflexionar...etc. Lo importante ya no es clasificar y describir, sino interpretar y explicar. Es cierto que este modelo es más fácil de implementar en los museos de arte contemporáneo, ya que en muchas ocasiones las obras contemporáneas llevan ya implícitas ideas como la participación, la apelación al espectador...etc. además de que tienen un lenguaje más cercano a un espectador actual y nos hablan sobre situaciones o reflexiones que en ocasiones podemos compartir. De ahí la importancia de que los museos de bellas artes encuentren esos nexos con los espectadores contemporáneos para que puedan reactivar, abrir y actualizar la temática y discursos de las obras. La realidad es que se debe asumir la heterogeneidad de los visitantes, por ello es esencial que el museo pueda ofrecer una experiencia social que se adapte en función de intereses y conocimientos para eliminar barreras de accesibilidad intelectual, cultural, sensorial...etc. Una programación expositiva variada y de amplia cobertura, así como la dinamización, a través de distintos medios, de las exposiciones y del espacio del museo permitirá alcanzar ese objetivo común.

\section{Lo que el museo pretende ser y lo que los espectadores perciben de él}

En 1969 Bourdieu inauguraría una serie de estudios sobre los visitantes de museos y sobre el consumo cultural. Aún a pesar de haber pasado más de 47 años los resultados que se obtuvieron continúan hoy en día siendo vigentes, pues los resultados que se obtienen en la actualidad al realizar estudios de hábitos culturales siguen siendo muy similares. En un sondeo realizado en 1989 por Duret-Robert ${ }^{3}$, en el que actualizaba los estudios de Bourdieu, una de las preguntas que se les hacía a los ciudadanos era: ¿cuál es el lugar público que

\footnotetext{
${ }^{2}$ HEIN. George E., (1992) The significance of Constructivism for museum education, in Musems and the Needs of the People. Jerusalem: CECA [en línea] [Consulta el 13-marzo-2015 ] Disponible en: https://www.exploratorium.edu/education/ifi/constructivist-learning

${ }^{3}$ DURET-ROBERT, 1989, Soundage pourquoi va-t-on dans les Musées?, Connaissance des Arts, n 449-450, 121-132. París.
} 
más te recuerda a un museo? La respuesta más frecuente fue una iglesia (41\%), seguida de una biblioteca (30,5\%) otros lugares $(11,5 \%)$ un ayuntamiento $(6,5 \%)$, una estación $(3,5 \%)$ una universidad $(2,5 \%)$ y una prefectura $(1,5 \%)$. Otra pregunta que se hacía era qué preferían ver cuando acudían a un museo, el resultado fue que una gran mayoría acudía a museos para ver pinturas antiguas $(46,5 \%)$, seguido de cuadros modernos $(25 \%)$, objetos de arte $(20 \%)$, muebles $(5,5 \%)$, arte popular $(2,5 \%)$ y coches antiguos $(0,5 \%)$

Las investigaciones sobre los visitantes de museos y la imagen que se asocia socioculturalmente a estos han venido siendo realizados mayoritariamente en el panorama anglosajón. Nacionalmente, en 2012 se comenzó a realizar una serie de estudios que adaptaban los realizados en la década de los 90 por Marillyn Hood en Inglaterra. El proyecto del Laboratorio Permanente de Público de Museos ${ }^{4}$, desarrollado por el Ministerio de Cultura, revela las imágenes que más frecuentemente se asocian al museo. En un primerísimo lugar, la idea que más se asocia es la de "arte" y "pintura". No obstante resulta paradójico que, los centros que más se citan no son museos, sino centros culturales como CaixaForum, CosmoCaixa... Los siguientes conceptos asociados son los de "historia" y "conocimiento". No obstante, un tercer grupo de palabras que aparece con bastante frecuencia es la de "aburrimiento", "cansancio", "cerrado". Un último grupo de palabras que aparece con menor frecuencia es la de "aglomeraciones", "colas", "turistas". Este último grupo de personas declara además que, la última vez que visitó un museo fue en un periodo de viaje. Entre los museos que se nombraban estaban presentes el del Prado, Louvre o museos Vaticanos.

Si como se ha estudiado, los museos de Bellas Artes son los más visitados, deberíamos entonces preguntarnos qué motivaciones reales animan a ese gran público a visitar el museo. Deberíamos preguntarnos si esa gran afluencia de gente no se debe a otra cosa que al cumplimiento de una convención ritual social y metacultural. Cuando se viaja a Madrid, se visita el Prado, al igual que se visita o fotografía la Puerta de Alcalá. Cuando se viaja a Italia se visitan los museos Vaticanos al igual que se acude a la Fontana de Trevi a lanzar una moneda para pedir un deseo...y así sucesivamente con distintas ciudades y sus respectivos museos y monumentos. El paso de dichos visitantes por el museo tiene, en su gran mayoría, poco interés real por observar con detenimiento un cuadro, de ahí que los conceptos que se vinculen a estos grandes museos sean las de imágenes estereotipadas como la frialdad, el cansancio, el aburrimiento y la sensación de encontrarse en un lugar cerrado. Ya ha habido algunos museos que para evitar la masificación y las desagradables condiciones de visita que esto desencadena ha puesto medidas, como por ejemplo: la venta de entradas limitadas, que se va a implementar en la Galería de los Uffizi, o la que se realizó durante la exposición de Leonardo da Vinci en la National Gallery, en la que las entradas para visitarla, se agotaron un año antes de que la exhibición se clausurara. ¿Son estas medidas un atentado a la democratización de la cultura, o por el contrario, una mejor forma de conservar las obras para que lleguen en óptimas condiciones al mayor número de personas posible (aún sabiendo que esto irá de la mano a una cierta elitización)?

\section{Sobre la actividad de los Museos de Arte Españoles}

Para conocer en qué situación se encuentran los museos de arte españoles en materia de dinamización y mediación, se han analizado un total de 38 museos estatales de Bellas Artes y Arte Contemporáneo, teniendo en cuenta los principales aspectos que inciden en la percepción de éstos en la ciudadanía: el sector de la población al que se dirige la programación, las características de su programación y los medios de difusión que utilizan. Se han excluido casas museo, museos catedralicios y museos que no disponen de colección. Así, se han analizado los museos de arte más representativos de cada autonomía. Los resultados más notorios son los siguientes:

- Un porcentaje muy bajo de museos de Bellas Artes (concretamente el $42,1 \%$ de la muestra) dispone de página web propia. Esto presenta dificultades a la hora de difundir su programación, pues normalmente en estos casos no se dispone de personal inscrito al museo que realice un mantenimiento y actualización de la web. En estos casos las webs son un subdominio de la sección de cultura de los distintos ayuntamientos autonómicos, lo que también dificulta la creación de una imagen corporativa clara, porque se encuentra difusa entre la de la propia imagen del ayuntamiento. En cuanto a actividad en redes sociales, también es considerable la diferencia en el uso que hacen de éstas los museos de Arte Contemporáneo frente a los de Bellas Artes. Los perfiles sociales más usados en ambos casos son los de facebook y twitter. No obstante, los índices de perfiles en twitter, instagram o youtube en los museos de Bellas Artes son considerablemente bajos, y presentan poca actividad (en un promedio de menos de una publicación a la semana), lo que dificulta en parte el engangement los seguidores potenciales y la creación de nuevos espectadores del museo.

- Así como la discapacidad física ya no es ninguna barrera en los museos analizados, continúan existiendo barreras para otros sectores sociales: Existe un porcentaje muy bajo de museos que tengan información adaptada a invidentes o discapacitados intelectuales ( $21 \%$ en el caso de los museos de Arte Contemporáneo y 31,6\% en museos de Bellas Artes). También el porcentaje de visitas guiadas adaptadas a estos grupos es bajo (47,4\% en los museos de Arte Contemporáneo y $36,8 \%$ en los museos de Bellas Artes)

\footnotetext{
${ }^{4}$ Laboratorio Permanente de Público de Museos, 2012. Conociendo a todos los públicos: ¿Qué imágenes se asocian a los museos? Madrid: Ministerio de Educación, Cultura y Deporte. NIPO: 030-12-330-1
} 
- En cuanto a las actividades programadas, destacar que pocos son los museos que dirigen alguna de sus actividades al sector de los jóvenes (de entre 15 a 25 años) y los mayores (a partir de 65 años). La mayor parte de actividades se planifican para escolares, familias o adultos.

\section{CONCLUSIONES}

\section{Museos para el público y público para el museo}

A pesar de lo expuesto anteriormente, es una labor complicada evaluar la implicación de la ciudadanía en los museos. No hay indicadores que nos permitan medir la permeabilidad que existe entre el museo y la población en la que se inscribe. Las estadísticas de visitantes nos aportan información superficial: las cifras no son capaces de evaluar si se está consiguiendo una acogida real en la población. Realizar otro tipo de estudios como estudios de público o estudios observacionales de visitantes que ayudara a esta labor conlleva una inversión que pocos museos pueden afrontar y por tanto, estos sistemas de evaluación aún son poco explorados por las instituciones museísticas españolas.

Aún a pesar de ello, es importante un replanteamiento de aspectos en la programación de actividades en los museos, así como en su museografía:

- Es preciso lograr captar la curiosidad de los potenciales visitantes. Es importante difundir la información y tener actualizada la programación tanto en la web propia como en las redes sociales, así como conseguir la aparición en prensa o agendas culturales: el público no es homogéneo, y por ello el plan de comunicación debe intentar llegar a él haciéndose visible de diversas formas.

- Hay que tener muy en cuenta el punto de mira de los espectadores considerando que no son solamente receptores de información. De ahí la importancia de tener una retroalimentación con la ciudadanía local. Para ello los medios tradicionales para visitar y participar del museo son insuficientes (catálogo, guías didácticas, guías pedagógicas...) Es interesante plantear espacios a proyectos comunitarios en los que puedan verse interesados e implicados asociaciones, colectivos o agrupaciones, con el fin de que sientan como propio el espacio del museo.

- Cuando se habla de actividades pedagógicas en un museo, inevitablemente pensamos en actividades para escolares. No obstante, hay un sector de la población que está creciendo exponencialmente y que está demandando una oferta de ocio cultural distinta a la que se les proporciona. Se trata de las personas con más de 60-67 años, en edad de jubilarse o ya jubilados. El museo puede convertirse en un instrumento capaz de mediar con este sector, aumentando su estima y favoreciendo su integración en la sociedad. Del mismo modo, propiciar un espacio de encuentro para los jóvenes (de entre 15 y 25 años), especialmente para los adolescentes, ayuda al museo a fomentar nuevos espectadores vinculados al futuro del museo.

- Para asegurar la accesibilidad universal sería necesario que las políticas culturales y de igualdad apoyaran programas para que los museos puedan incorporar contenido adaptado para los sectores invidentes, discapacitados psíquicos, sordos y ciegos.

Aún así, no todo está en manos de los museos: es importante que la ciudadanía consiga despojarse de viejos prejuicios y que participen en las actividades promovidas a estos.

\section{FUENTES REFERENCIALES.}

AA.VV. Laboratorio Permanente de Público de Museos, 2012. Conociendo a todos los públicos: ¿Qué imágenes se asocian a los museos? Madrid: Ministerio de Educación, Cultura y Deporte. NIPO: 030-12-330-1

AMADO DA SILVA GARCÍA, Roseli, 2015. Proyecto Linha do Abraço: ejercicios poéticos de mirar, sentir y de construir en la confluencia museo comunidad. Congreso Internacional de Investigación en Artes Visuales ANIAV $2015 . \quad$ DOI: http://dx.doi.org/10.4995/ANIAV.2015.1285

DURET-ROBERT, 1989, Soundage pourquoi va-t-on dans les Musées?, Connaissance des Arts, no 449-450, 121-132. París.

HEIN, G.E., 1999. The constructivist Museum. En E. Hooper Greenhill, The educational Role of the Museum (2a ed., pp. 73-79). New York: Routledge 
El Museo como escuela de espectadores. La ciudadanía en los Museos de Arte

III CONGRESO INTERNACIONAL DE INVESTIGACIÓN EN ARTES VISUALES :: ANIAV 2017 :: GLOCAL [codificar, mediar, transformar, vivir] http://dx.doi.org/10.4995/ANIAV.2017.5825

HERNANDEZ CARDONA, Francesc Xavier y SANTACANA MESTRE, Joan, 2006. Museología crítica. Gijón: Ediciones Trea. ISBN: 84-9704226-3

SIMON, Nina, 2010. The Participatory Museum. California: Museum 2.0. ISBN: 978-0-615-34650-2 